Supplement of Biogeosciences, 17, 887-899, 2020

https://doi.org/10.5194/bg-17-887-2020-supplement

(C) Author(s) 2020. This work is distributed under

the Creative Commons Attribution 4.0 License.

(c) (i)

Supplement of

\title{
Intercomparison of four methods to estimate coral calcification under various environmental conditions
}

Miguel Gómez Batista et al.

Correspondence to: Miguel Gómez Batista (mgomezbatista@gmail.com)

The copyright of individual parts of the supplement might differ from the CC BY 4.0 License. 


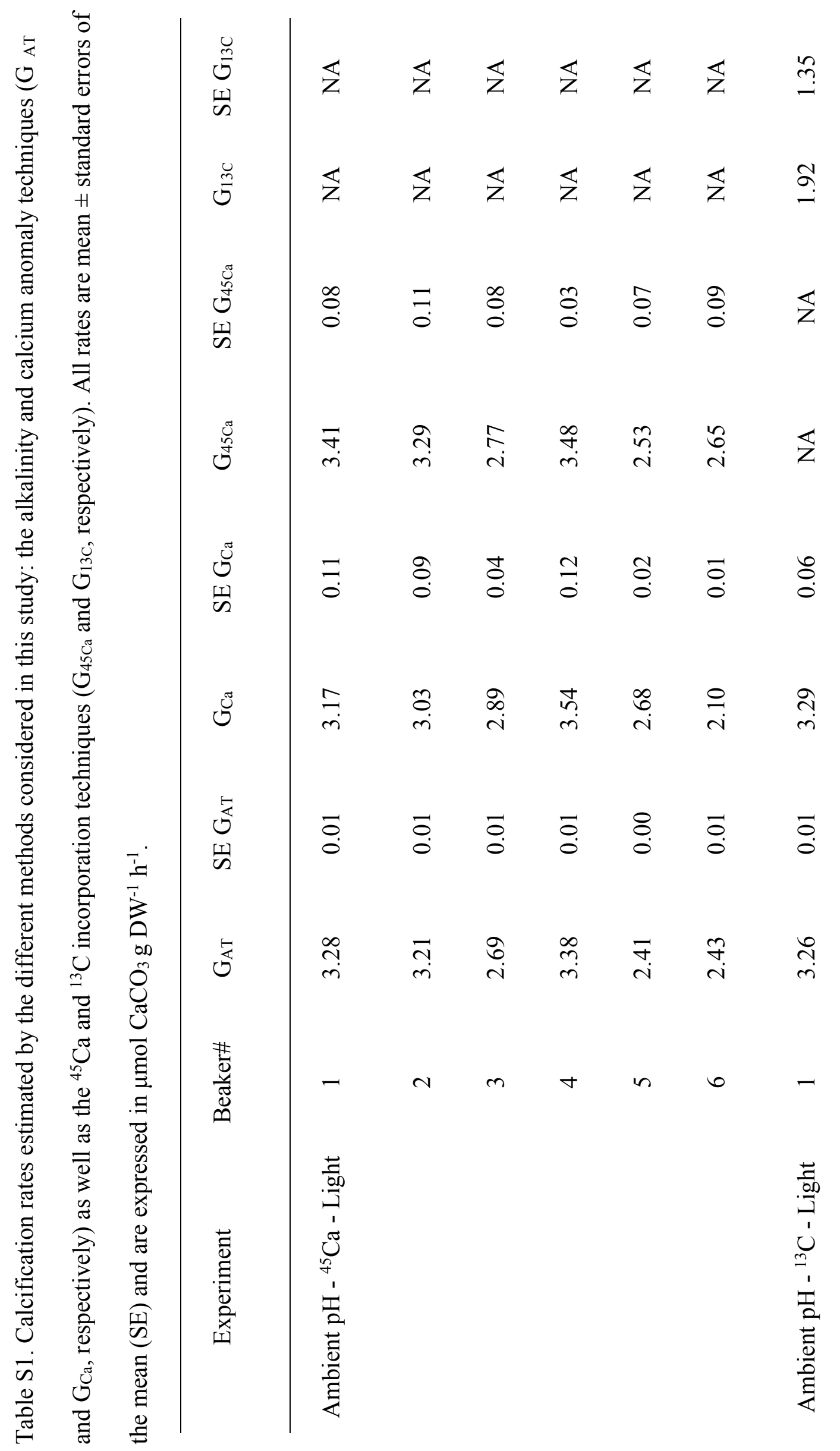


तิ

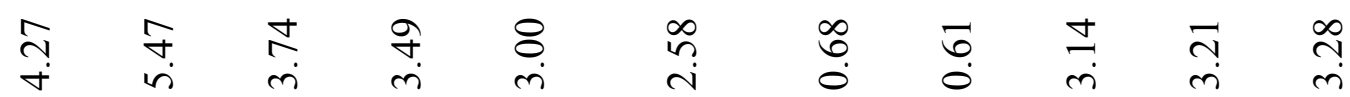

$\begin{array}{lllllllllll}\mathbb{z} & \mathbb{z} & \mathbb{z} & \mathbb{z} & \mathbb{z} & \mathbb{z} & \mathbb{z} & \mathbb{z} & \mathbb{z} & \mathbb{z} & \mathbb{z}\end{array}$

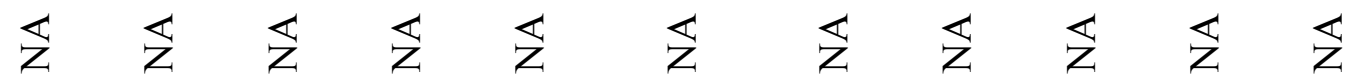

ڤ.

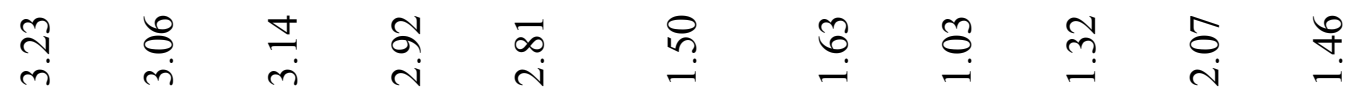

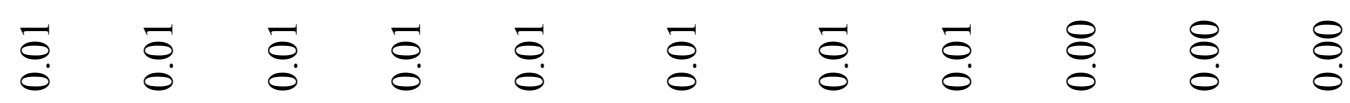

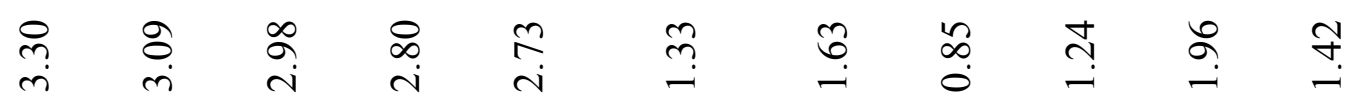

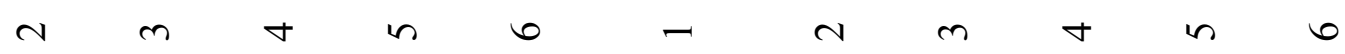

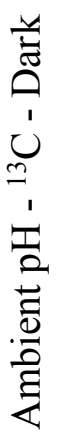




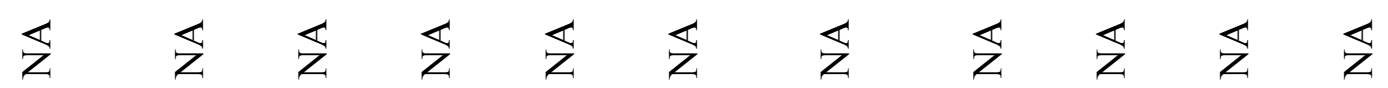

妾

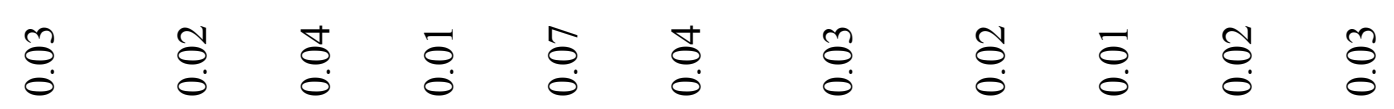

每

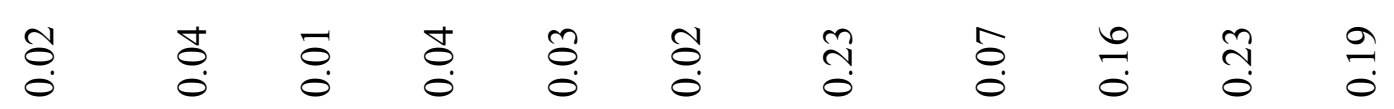

ำ

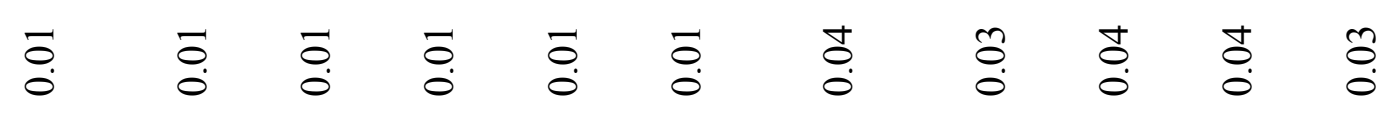

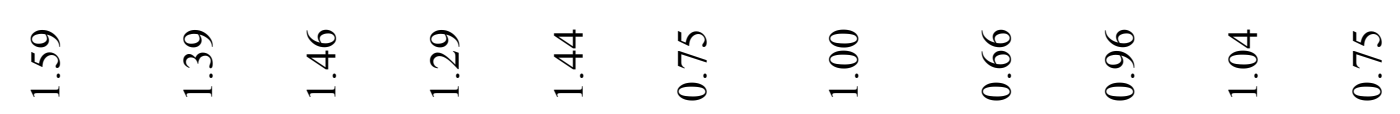

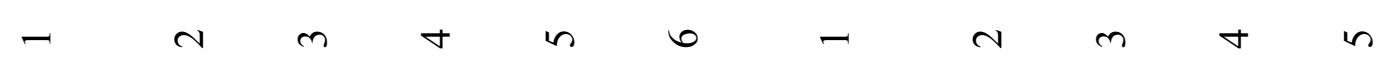

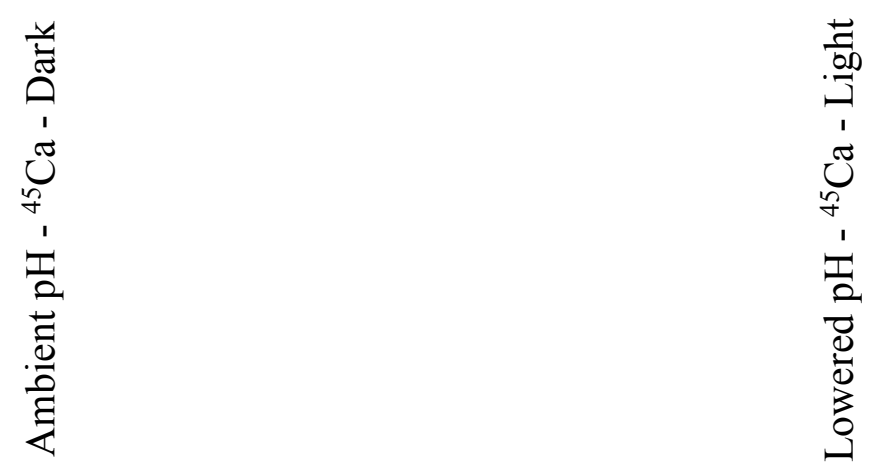




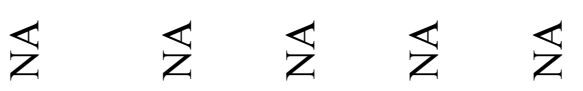

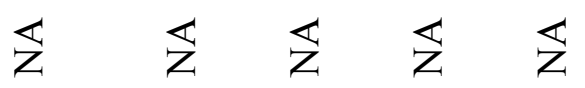

\& $8: 5 \%$

范 索

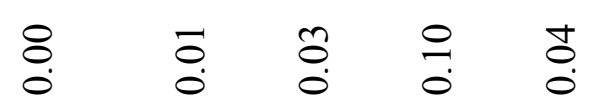

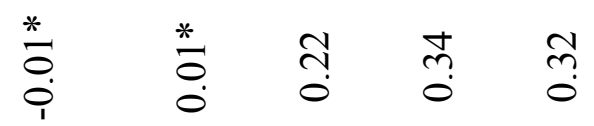

ఏ)

苦 龸

- $\quad m \quad$ n

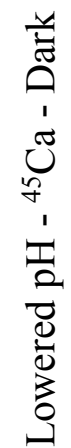

